\title{
MEDIUM - TERM RESULTS OF CORONARY ARTERY BYPASS SURGERY IN PATIENTS WITH SEVERE LEFT VENTRICULAR DYSFUNCTION AND PREOPERATIVELY DOCUMENTED HIBERNATING MYOCARDIUM
}

\author{
Jan Knap, Jan Harrer \\ Department of Cardiac Surgery, Charles University Faculty of Medicine and Teaching Hospital, Hradec Králové; \\ (Head: prof. MUDr. J. Dominik, CSc.)
}

\begin{abstract}
Summary: In patients with multivessel coronary artery disease (CAD), severe left vetricular dysfunction (LVD) and hibernating myocardium (HM) demonstrated on preoperative assessment, coronary artery bypass grafting (CABG) surgery can be performed safely with low operative morbidity and mortality rates. Surgical revascularization of reversibly dysfunctional myocardium improves significantly both patient's clinical status and left ventricular ejection fraction (LVEF). Diagnosis of HM prior to CABG surgery seems to be crucial because it does not leave the patient with multivessel CAD and LVD a candidate only for heart transplantation (HTX). In the presence of HM, more agressive surgical approach could be recommended to salvage chronically jeopardised but viable myocardium using not only routine $\mathrm{CABG}$ procedures in extracorporeal circulation (ECC) but also alternative approach of coronary endarterectomy (EAE) or minimally invasive direct coronary artery bypass grafting (MIDCAB) procedures on beating heart, without any adverse impact on operative mortality.
\end{abstract}

Key words: Coronary Artery Disease; Left Ventricular Dysfunction; Hibernating Myocardium; Coronary Artery Bypass Surgery; Coronary Endarterectomy; Minimally Invasive Myocardial Revascularization

\section{Introduction}

The important role of left ventricular (LV) function as a prognostic indicator in patients with CAD has been illustrated in a number of studies $(1,3,5,7,15,25,26)$.

Results of large registries and randomized trials comparing $C A B G$ surgery and medical therapy have suggested improved survival in patients with reduced LVEF and multivessel CAD treated with surgery $(2,6)$. However, especially these patients have shown increased surgical risk and lower operative and long - term survival rates than those with normal LVEF (20).

In patients with poor LV function, medical treatment carries a bleak long - term prognosis despite recent advances in farmacological therapy $(15,26,32)$. An estimated 2 - year survival rate in this group of patients is about $30 \%$ (34). Although HTX is an attractive option for end - stage ischemic cardiomyopathy, limited donor availability, strict indication criteria and high mortality rate among patients on waiting lists make HTX a very limited option $(8,20,21,23)$.

Over the past decade it has become clear that chronic LVD is not necessarily an irreversible process $(1,5)$. As a result, the concept of myocardial hibernation was introduced by Rahimtoola to describe „a state of significantly impaired $\mathrm{LV}$ function at rest due to persistent reduction of coronary blood flow which can be partially or completely restored to normal by improving blood flow or by reducing oxygen demand“ (29). In his theory, based on clinical observations, hibernation was described as down-regulation of myocardial function which represented an attempt by myocytes to balance oxygen supply and demand by reducing oxygen consumption, thus preventing myocardial necrosis and ischemic symptoms at rest $(30,31)$. According to various authors, recovery of dysfunctional myocardium in areas of hibernation after revascularization can take several days, weeks or even months to occur following blood flow restoration $(16,22,31)$.

The current clinical challenge is to identify those high risk patients with multivessel CAD, severe LDV and preoperatively demonstrated HM who are likely to derive greatest functional and prognostic benefit from CABG surgery $(11,12,13,28)$. Moreover, minimizing perioperative and postoperative complications associated with high-risk surgery seems to be another reasonable endpoint to assess myocardial viability in patients with severe LVD prior to CABG $(19,31)$. In patients with preoperatively identified HM, even coronary EAE could be fully justified in order to revascularize reversibly dysfunctional myocardium (14). Furthermore, MIDCAB procedure could be an attractive surgical option, especially when dealing with a very selective group of high - risk patients who suffer from severe is- 
chemic but reversible LVD and various comorbidities (e.g. chronic renal dysfunction, lung dysfunction, liver dysfunction, peripheral vascular disease, previous stroke, severe aortic atherosclerotic disease) where standard $\mathrm{CABG}$ surgery in extracorporeal circulation (ECC) may be contraindicated $(3,24,33)$.

\section{Patients and methods}

\section{Study objective}

The objective of the present pilot study was to evaluate early and medium - term results of CABG surgery in patients with multivessel CAD, severe LVD and preoperatively documented HM.

\section{Design}

Prospective evaluation (early and medium postoperative outcome) of all patients with severe LVD and preoperatively documented HM who underwent CABG procedure from April 1996 to April 1998 and were referred to the Follow - up Clinic for regular postoperative check - up.

\section{Preoperative data}

Seventeen patients ( 16 men, 1 woman, mean age $61.9 \pm$ 6.9) with multivessel CAD and preoperative mean LVEF of $28.5 \pm 7.1$ (range 16 to $38 \%$ ) were studied and $\mathrm{HM}$ as a reversible cause of LVD was demonstrated. Preoperatively all patients had a history of myocardial infarction (100\%). Preoperatively the mean NYHA functional class was $3.1 \pm 0.4$ and the mean left ventricular end - diastolic pressu-

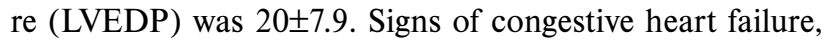
especially dyspnea were present in 16 patients $(94.2 \%) ; 11$ of our patients $(64.7 \%)$ suffered from angina pectoris. Nine patients $(52.9 \%)$ had mild to moderate degree of mitral regurgitation preoperatively classified as ischemic without any valvular morphological changes (Table 1). All patients were preoperatively screened for the presence of HM using a stress echocardiography scan with low - dose dobutamine (5 - $10 \mu \mathrm{g} / \mathrm{kg} / \mathrm{min}$ ) and „parietoseptography“ assessment from coronary angiogram.

Table 1:

\begin{tabular}{|l|l|}
\hline Preoperative data & $\mathrm{n}=17$ \\
\hline Age (years) & $61.9 \pm 6.9$ \\
\hline Sex: male & $16 / 17(94.2 \%)$ \\
\multicolumn{1}{|c|}{ female } & $1 / 17(5.8 \%)$ \\
\hline Prior myocardial infarction & $17 / 17(100 \%)$ \\
\hline NYHA functional class & $3.1 \pm 0.4$ \\
II & $1 / 17(5.8 \%)$ \\
III & $14 / 17(82.4 \%)$ \\
IV & $2 / 17(11.8 \%)$ \\
\hline LVEF (\%) & $28.5 \pm 7.1$ \\
\hline LVEDP (mm Hg) & $20 \pm 7.9$ \\
\hline Multivessel CAD & $17 / 17(100 \%)$ \\
\hline Ischemic mitral regurgitation & $9 / 17(52.9 \%)$ \\
\hline
\end{tabular}

\section{Operative management:}

Fourteen patients $(82.4 \%)$ underwent isolated CABG using a standard operative technique without any other open heart procedure. Routine ECC was commenced with aortic and two - stage venous cannulas. Myocardial preservation was performed by moderate systemic hypothermia $\left(28-30^{\circ} \mathrm{C}\right)$; antegrade cold crystalloid, and more recently in 5 patients, blood cardioplegia were administered into ascending aorta after aortic cross - clamping. Topical pericardial cooling with ice was used as an adjunct. Three patients (17.6\%) underwent a minimally invasive bypass grafting on beating heart; through median sternotomy approach in one case and through left anterior small thoracotomy /LAST/ approach in two cases, without using heart - lung machine The number of distal anastomoses carried out per patient was 2.7 (range 1 - 4) always aiming at complete revascularization. The left IMA (LIMA) was used in 11 patients $(64.7 \%)$. Coronary EAE was performed in 2 patiens $(11.8 \%)$

\section{Follow - up}

All patients were followed up ( $100 \%$ follow - up) for 2.9 to 24.5 months (the mean follow - up 17.1 months). The follow - up included assessment of survival, clinical status (NYHA classification) using a routine clinical check - up and LVEF from a standard transthoracic echocardiography scan.

\section{Results}

\section{Postoperative data}

In 16 patients $(94.2 \%)$ we used dopamine infusion for perioperative and early postoperative inotropic support. Intraaortic baloon pumping (IABP) was used peri - and postoperatively only in one patient $(5.8 \%)$.

\section{Mortality}

None patient died within 30 days postoperatively. One patient could be weaned from ECC only with inotropic and IABP support; on the 6th postoperative day he developed respiratory distress syndrome (ARDS) and needed longer ventilatory support. Except of that there were no other significant non-lethal complications present during early postoperative period.

\section{Late mortality}

During the follow - up period ranged from 2.9 to 24.5 (the mean 17.1 months) there was no death in the studied group. Thus, survival rate was $100 \%$. The mean LVEF increased postoperatively from $28.5 \pm 7.1$ to $44.8 \pm 7.8$ $(\mathrm{p}<0.0001)$. The mean NYHA functional class improved from $3.1 \pm 0.4$ preoperatively to $1.6 \pm 0.7$ postoperatively $(p<0.0001)$. None patient needed any interventional procedure, redo CABG nor HTX during follow - up period. The summarised postoperative data are tabulated in Table 2 . 
Table 2:

\begin{tabular}{|l|l|}
\hline Postoperative data & $\mathrm{n}=17$ \\
\hline Dopamin postoperatively & $16 / 17(94.2 \%)$ \\
\hline IABP & $1 / 17(5.8 \%)$ \\
\hline Number of distal anastomoses & $2.7(1-4)$ \\
\hline LIMA & $11 / 17(64.7 \%)$ \\
\hline EAE & $2 / 17(11.8 \%)$ \\
\hline MIDCAB & $3 / 17(17.6 \%)$ \\
\hline Mortality: & \\
1. Early (30 - day mortality) & $0 / 17(0 \%)$ \\
2. Late & $0 / 17(0 \%)$ \\
\hline Mean Follow - up (months) & $17.1(2.9-24.5)$ \\
\hline LVEF (\%) & $\mathbf{4 4 . 8} \pm 7.8(\mathrm{p}<0.0001)$ \\
\hline NYHA functional class & $\mathbf{1 . 6} \pm \mathbf{0 . 7}(\mathrm{p}<0.0001)$ \\
I & $9 / 17(52.9 \%)$ \\
II & $6 / 17(35.3 \%)$ \\
III & $2 / 17(11.8 \%)$ \\
\hline PTCA or redo CABG & $0 / 17(0 \%)$ \\
\hline HTX & $0 / 17(0 \%)$ \\
\hline
\end{tabular}

\section{Discussion}

Advanced CAD and ischemic cardiomyopathy are criteria of a severe illness (18). However, in selected cases surgical revascularization has proved beneficial in terms of survival, reduction of morbidity and lowering the frequency of angina in numerous studies over past two decades $(17,19,20,27,28)$. Despite increased surgical risk and higher long - term mortality rates than patients with normal LVEF, patients with LVD and multivessel CAD undergoing CABG surgery have shown improved outcome compared with those treated medically $(1,28)$.

Severe LVD can be result either of myocardial necrosis or myocardial hibernation $(16,31)$. The noninvasive assessment of myocardial viability has been shown clinically useful for demonstrating residual myocardial viability and predicting improvement in global and regional LVEF after CABG surgery in patients with significant LVD $(2,3,4,6)$. The currently most frequently used techniques include scintigraphic imaging with either positron emission tomography (PET) or single photon emission computed tomography (SPECT) and stress echocardiography during stepwise infusion of dobutamine (DSE) $(6,9,10,33)$. The results obtained from these techniques are more - less comparable in preoperative identification of viable myocardium $(2,3,4)$.

Only if viability can be demonstrated, are revascularization procedures fully justified $(2,3)$. Few recent studies have shown that the greater the number of viable myocardial segments detected by any diagnostic tool the greater the probability of improvement in LVEF following CABG and thus, better short- and long-term outcome after CABG than in similar patients with lesser amounts of viability $(13,28)$. On the other hand, patients with a depressed LV function and extensive myocardial viability treated medi- cally have a high cardiac event rate. Similarly, patients with poor viability who still undergo $\mathrm{CABG}$ procedure have a high rate of early and late cardiac deaths or need for HTX compared with patients with greater viability $(13,28)$

Furthermore, some studies have also clearly shown that patients with ischemic cardiomyopathy who have extensive zones of viable (hibernating) myocardium have a significantly better outcome following CABG surgery than do those treated medically, as reflected by enhanced survival, improvement in symptoms of heart failure and increased exercise capacity $(12,17,18,28)$. Another conclusion that can be drawn is that patients with predominantly nonviable myocardium have a rather poorer long-term outcome following $\mathrm{CABG}$ (28). Rejecting such patients from surgery should result in a reduction in costs as a result of avoiding surgical interventions that are unlikely to be of major shortterm or long-term benefit. Thus, these patients are the ultimate candidates only for HTX (8). Future prospective studies might help in providing more specific data to prove these assumptions and to assist in clinical decision making (28).

Medical management of HM does not result in improvement in symptoms and LV performance deteriorates over time without revascularization (13).

\section{Study limitations}

The present pilot study evaluated early and medium term postoperative results in symptom profile and LVEF changes in a highly selected population of patients with multivessel CAD, severe LVD and preoperatively demonstrated HM who underwent CABG surgery. The selection of therapy was made not on randomised basis, but on clinical basis alone. In addition, this study specifically excluded patients who underwent combined open heart procedures.

Limitations of the present pilot study are based on a small number of patients and also on a very selected population. It does not compare outcome of the patients included in the study with a similar cohort of patients who were not treated with surgery. Therefore, it could not provide guidance for selection of such high - risk patients either for $\mathrm{CABG}$ surgery or medical therapy. Another limitation of the study is that we did not use any of scintigraphic imaging scans in addition to DSE to increase the probability of tissue viability detection.

\section{Conclusions}

CABG surgery may be offered even to patients with severely depressed LV function if the presence of $\mathrm{HM}$ as a reversible cause of LVD has been identified by any of diagnostic tools. Viability assessment in patients with multivessel CAD and severe LVD prior to CABG surgery seems to be crucial because it does not leave the patient with multivessel CAD and LVD a candidate only for HTX. In the presence of HM, more agressive surgical approach 
could be recommended to salvage chronically jeopardised but viable myocardium using not only routine revascularization surgical techniques in ECC but also alternative approach of coronary EAE or MIDCAB grafting on beating heart, without any adverse impact on operative mortality.

We are encouraged by our premilinary results to continue in the direction of preoperative viability assessment in this highly selected group of patients. If HM is preoperatively identified, routine surgical revascularization could be employed and the results in terms of low mortality as well as excellent outcome may be expected. On the other hand, in patients with reversible ischemic LVD who have significant comorbidities that significantly increase the risk of a standard surgical intervention, MIDCAB procedure without using heart - lung machine can be considered as an alternative treatment to revascularize viable myocardium.

\section{References}

1.Alderman EL, Fisher LD, Litwin P et al. Results of coronary artery surgery in patients with poor left ventricular function (CASS). Circulation 1983;68:785-95.

2.Bax JJ, van Eck-Smit BLF, van der Wall EE. Assessment of tissue viability: clinical demand and problems. Eur Heart J 1998;19;847-58.

3.Beller GA. Assessment of myocardial viability. Current Opinion in Cardiol 1997; 12:459-67.

4.Bonow RO: Identification of viable myocardium. Circulation 1996;94:2674-80.

5.Braunwald E, Rutherford JD. Reversible ischemic left ventricular dysfunction: Evidence for the „hibernating myocardium“. J Am Coll Cardiol 1986;8:1467-70.

6.Cigarroa CG, deFilippi CR, Brickner ME, Alvarez LG, Wait MA, Grayburn PA. Dobutamine stress echocardiography identifies hibernating myocardium and predicts recovery of left ventricular function after revascularization. Circulation 1993;88:430-36.

7.Cohn PF, Gorlin R, Cohn LH, Collins JJ Jr. Left ventricular ejection fraction as a prognostic guide in the surgical treatment of coronary and valvular heart disease. Am J Cardiol 1974;34:136-41.

8.DeNofrio D, Loh E. Myocardial viability in patients with coronary artery disease and left ventricular dysfunction: transplantation or revascularization? Current Opinion in Cardiology 1996;11:394-402.

9.Di Carli MF, Davidson M, Little R et al. Value of metabolic imaging with positron emission tomography for evaluating prognosis in patients with coronary artery disease and left ventricular dysfunction. Am J Cardiol 1994;73:527-33.

10.Dilsizian V, Bonow RO. Current diagnostic techniques of assessing myocardial viability in hibernating and stunned myocardium. Circulation 1993;87:1-20.

11.Dreyfus GD, Duboc D, Blasco A et al. Myocardial viability assessment in ischemic cardiomyopathy: benefits of coronary revascularization. Ann Thorac Surg 1994;57: 1402-8.
12.Eitzman D, Al-Aouar Z, Kanter HL. Clinical outcome of patients with advanced coronary artery disease after viability studies with positron emission tomography. J Am Coll Cardiol 1992;20:559-65.

13.Gunning MG, Chua TP, Harrington D et al. Hibernating myocardium: clinical and functional response to revascularization. Eur J Cardio-thorac Surg 1997;11:1105-12.

14.Harrer J. Chirurgická léčba difuzního postižení koronárního řečiště. Sb Ved Pr (Suppl.)Lek Fak Univerzity Karlovy Hradec Králové 1992;35:367-74.

15.Harris PJ, Harrel FE, Lee KL, Bekar VS, Rosati RA. Survival in medically treated coronary artery disease. Circulation 1979;59:421-30.

16.Hearse D: Myocardial ischemia: Can we agree on a definition for the 21st Century? Editorial. Cardiovasc Res 199428:1737-44.

17.Christenson JT, Maurice J, Simonet F et al. Effect of low ventricular ejection fractions on the outcome of primary coronary bypass grafting in end-stage coronary artery disease. J Cardiovasc Surg 1995;36:45-51.

18.Kleikamp G, Posival H, Minami K, El-Banayosy A, Körfer R: Ischemic cardiomyopathy-revascularization vs. transplantation. Eur J Cardio-thorac Surg 1997;11(Suppl.):S1-S4.

19.Lee KS, Marwick TH, Cook SA et al: Prognosis of patients with left ventricular dysfunction, with and without viable myocardium after myocardial infarction: relative efficacy of medical therapy and revascularization. Circulation 1995;90:2687-94.

20.Louie H, Laks H, Milgalter E et al. Ischemic cardiomyopathy:criteria for coronary revascularization and cardiac transplantation. Circulation 1991;84(Suppl 3):290-95.

21.Luu M, Stevenson L, Brunken R, Drinkwater D, Schelbert H, Tilsch J. Delayed recovery of revascularized myocardium after referral to cardiac transplantation. Am Heart J 1990;119:668-70.

22.Marban E: Myocardial stunning and hibernation. Circulation 1991;83:681-8.

23.Mickleborough L, Maruyama H, Takagi Y, Mohamed S, Sun Z, Ebisuzaki L: Results of revascularization in patients with severe left ventricular dysfunction. Circulation 1995;92(Suppl 2):73-9.

24.Moshkovitz Y, Sternik L, Paz Y et al. Primary coronary bypass grafting without cardiopulmonary bypass in impaired left ventricular function. Ann Thorac Surg 1997;63(Suppl.6):S44-7.

25.Murray JA, Chinn N, Peterson DR. Influence of left ventricular function on early prognosis in atherosclerotic heart disease (abstr). Am J Cardiol 1974;33:159.

26.Nelson GR, Cohn PF, Gorlin R. Prognosis in medically treated coronary artery disease: the value of ejection fraction compared with other measurements. Circulation 1975;52:408-12.

27.Nollert G, Schmoeckel A, Markewitz A et al. Surgical therapy of coronary artery disease in patients with a left ventricular ejection fraction of $25 \%$ or less. J Cardiovasc Surg 1997;38:389-95. 
28.Pagley PR, Beller GA, Watson DD, Gimple LW, Ragosta M. Improved outcome after coronary bypass surgery in patients with ischemic cardiomyopathy and residual moycardial viability. Circulation 1997;96:793-800.

29.Rahimtoola SH. A perspective on three large multicenter randomized clinical trials of coronary bypass surgery for chronic stable angina. Circulation 1985;72(Suppl V):123-35. 30.Rahimtoola SH. From coronary artery disease to heart failure: role of the hibernating myocardium. Am J Cardiol 1995; 75:16E-22E.

31.Rahimtoola SH. The hibernating myocardium. Am Heart J 1989;117:211-21.

32.Shapira I, Isakov A, Yakirevich V, Topilsky M. Longterm results of coronary artery bypass surgery in patients with severely depressed left ventricular function. Chest 1995;108(6):1546-50.
33. Schelbert H. Metabolic imaging to assess myocardial viability. J Nucl Med 1994;35(Suppl 4):8S-14S.

34.Winkel E, Piccione W. Coronary artery bypass surgery in patients with left ventricular dysfunction: candidate selection and perioperative care. J Heart Lung Transplant 1997;16(6):S19-24.

Submitted August 1998.

Accepted September 1998.

\author{
MUDr. Jan Knap, \\ Hradecká 1124, \\ 50002 Hradec Králové, \\ Czech Republic.
}

